\title{
METHODOLOGIC ISSUES
}

\section{Setting priorities in injury prevention: the application of an incidence based cost model}

\author{
S Mulder, W J Meerding, E F van Beeck
}

Injury Prevention 2002;8:74-78

\begin{abstract}
Objectives: To make detailed calculations on the direct medical costs of injuries in the Netherlands to support priority setting in prevention.

Methods: A computerised, incidence based model for cost calculations was developed and incidence figures derived from the Dutch Injury Surveillance System (LIS) which provides national estimates of the annual number of patients treated at an emergency department. A comprehensive set of cost elements (that is, health care segments) was obtained from health care registrations and a LIS patient survey. Patients were assigned to specific groups based on LIS characteristics (for example, age, injury type). Average costs per patient group were calculated for each cost element and total costs estimated by adding costs for all patient groups. Results: The direct costs of injury average 2000 guilders per injury patient attending an emergency department. Home and leisure injuries account for over half of the costs, although cost per patient is highest for motor vehicle injuries. Injuries to the lower extremities account for almost half of the total costs and are incurred mainly in the home or recreation. Motor vehicle crashes are the major cause of head injuries.

Conclusions: The model permits continuous and detailed monitoring of injury costs. Estimates can be compiled for any LIS patient group or injury subcategory. The results can be used to rank injuries for prioritisation of prevention by injury categories (for example, traffic, home, or leisure), or by specific scenarios (for example, fall at home).
\end{abstract}

See end of article for authors' affiliations

Correspondence to:

Dr Saakje Mulder

Consumer Safety Institute,

PO Box 75169, 1070 AD

Amsterdam, the

Netherlands;

S.Mulder@consafe.nl

$\mathrm{P}$ ublic health in the Netherlands improved remarkably in the 20th century with around 30 years added to average life expectancy. At the same time, new health threats have arisen associated with increased prosperity, and in particular, with changed lifestyles and new environmental risks. Injuries are among these and accounted for $16 \%$ of deaths worldwide in the 1990s.

The Dutch Injury Surveillance System (LIS) maps the nature and extent of injuries and their main causes. LIS covers all injured patients who attend the emergency department of 17 hospitals in the Netherlands, and is used to make national estimates. ${ }^{23}$ This paper addresses the economic consequences of intentional and unintentional injuries for the health care sector and hence for society as a whole. The cost of medical treatment is only one element of the total societal burden of injuries, but it is one of the most directly visible.

Previous studies have examined the costs of injury in the Netherlands. Physical injuries ( 2.5 billion guilders; 1 guilder is equal to almost $€ 0.5$ ) accounted for $4 \%$ of the total healthcare budget in $1994 .{ }^{4}$ In $1988,8 \%$ of indirect costs (loss of productivity) were a direct result of injuries. ${ }^{5}$ Other countries have also studied injury costs. ${ }^{5-10}$ A recent United States survey estimates the societal costs associated with consumer product injuries alone to be $\$ 517$ billion. ${ }^{1}$

Although the total costs of injury in the Netherlands are known, there was no model to estimate these costs so that they could be used for priority setting in injury prevention. This project had the explicit aim of developing a computerised model to estimate the direct medical costs (that is, the costs within the healthcare sector) of injuries in the Netherlands. In addition to type of information generated by the model, this paper examines:

- Total costs of injury and costs per injury patient and how these estimates compare to incidence figures.

- Incidence and costs by injury category.

- Incidence and costs by injury type.
- Identification of specific scenarios for potential intervention.

\section{METHODS}

We used an "incidence based approach" to estimate the (lifetime) costs of all injuries that occur within a specific period. ${ }^{12}{ }^{13}$ The model is based on the incidence of injuries treated in emergency departments in 1997, as recorded in LIS.

Injury incidence is classified by predefined patient groups on the basis of medical cost determinants: initial care (admitted/not admitted), location/type (39 categories), age, sex, and severity (using indicators, such as the involvement in a motor vehicle crash).

For patient groups, costs are calculated by multiplying the incidence by the average medical cost per patient, estimated on the following three parameters: transition probabilities (for example, chance of hospitalisation), volume of care (for example, average duration of nursing), and unit cost prices (for example, one day of nursing).

This procedure is performed for all segments within the health care sector. Table 1 provides a list of these segments in addition to the transition probabilities and major data sources used. Altogether 9828 patient groups were identified. After omitting those with no predictive value, a range of between two (use of antibiotics) and 546 (inpatient care) groups were defined.

Apart from LIS, surveillance systems with national coverage of injury patients admitted to hospitals (LMR), rehabilitation centres (LIVRE), and to nursing homes (SIVIS $)^{14-16}$ were used

Abbreviations: LIS, Dutch Injury Surveillance System; LMR, National Database of Hospitalised Patients, LIVRE, National Information System for Rehabilitation; SIVIS, National Nursing Home Information System 
Table 1 Transition probabilities and data sources in health care sector

\begin{tabular}{|c|c|c|}
\hline Health care segment & Transition probabilities & Sources (ref) \\
\hline \multicolumn{3}{|l|}{ 1. General practitioner } \\
\hline Referral to ED & $\%$ Referred & 34, Patient survey \\
\hline Follow up & & Patient survey \\
\hline \multicolumn{3}{|l|}{ 2. Ambulance transport } \\
\hline Emergency transport & \% Transported to ED & 34 \\
\hline \multicolumn{3}{|l|}{ 3. Hospital care } \\
\hline ED & NA & 34,35 \\
\hline Other outpatient care & $\%$ Outpatient care & 34, Patient survey \\
\hline Day care & \% Day care & 16 \\
\hline Inpatient care & $\%$ Admitted & 16 \\
\hline Inpatient therapeutic procedures & $\%$ Inpatient procedures & 16 \\
\hline \multicolumn{3}{|l|}{ 4. Rehabilitation } \\
\hline Outpatient rehabilitation & $\%$ Outpatient rehabilitation & 17 \\
\hline Inpatient rehabilitation & $\%$ Inpatient rehabilitation & 17 \\
\hline 5. Nursing home care & $\%$ Admitted & 18 \\
\hline 6. Outpatient physiotherapy & \% Physiotherapy & Patient survey \\
\hline \multicolumn{3}{|l|}{ 7. Home care } \\
\hline Household assistance & $\%$ Consumption household assistance & Patient survey \\
\hline Nursing & $\%$ Consumption nursing & Patient survey \\
\hline \multicolumn{3}{|l|}{ 8. Pharmaceuticals } \\
\hline Painkillers & \% Consumption painkillers & Patient survey \\
\hline Antibiotics & $\%$ Consumption antibiotics & Patient survey \\
\hline
\end{tabular}

to estimate the transition probabilities of defined patient groups and volume of care. All costs in the first year after injury could be calculated for these three sectors. To estimate the use of different types of outpatient care, a follow up survey was conducted among a random sample of 5800 LIS patients (response $40 \%)^{17}$ two, five, and nine months after injury. Logistic regression was used to adjust for non-response. Finally, various financial sources were used to estimate costs. ${ }^{4}{ }^{18-24}$

The calculation method works as follows: A LIS patient is assigned to a patient group for each cost element. The average costs per patient group (transition probability $\times$ volume of care $\times$ unit cost price) are then calculated for each cost element. The cumulative costs per patient are then calculated over all elements. Total cost is obtained by adding costs for all patients. This estimate can be compiled for any selection of LIS patients (for example, those from a specific scenario).

The general structure of the model (especially the selection of cost elements and the composition of patient groups) was developed in cooperation with the European Working Group on the Cost of Injury. ${ }^{25} 26$

\section{RESULTS}

Incidence, total costs, and costs per injury patient

In 1997 l.1 million injury patients were treated at emergency departments and 104000 patients were admitted to hospital in the Netherlands. The total direct medical costs of injury are

Table 2 Incidence, total costs (million guilders, Dfl), and costs per patient by injury category, injury type, and scenario in the Netherlands 1997

\begin{tabular}{llll}
\hline & Incidence (\%) & Costs (million Dfl) (\%) & Costs per patient (Dfl) \\
\hline Category & & & \\
Traffic & $140000(13.0)$ & $408(18.7)$ & 2900 \\
Home and leisure & $580000(53.3)$ & $1281(58.8)$ & 2200 \\
Sport & $180000(17.0)$ & $206(9.5)$ & 1100 \\
Occupational & $110000(10.2)$ & $112(5.1)$ & 1000 \\
Intentional & $54000(4.9)$ & $99(4.5)$ & 1800 \\
Unknown & $17000(1.6)$ & $72(3.3)$ & - \\
Total & $1100000(100)$ & $2177(100)$ & 2000 \\
Type & & & \\
Head & $47000(4.3)$ & $168(7.7)$ & 3600 \\
Face & $97000(8.9)$ & $66(3.0)$ & 12300 \\
Vertebral column/spinal cord & $5400(0.5)$ & $67(3.1)$ & 6500 \\
Trunk & $9600(0.9)$ & $62(2.9)$ & 2000 \\
Upper extremities & $184000(16.9)$ & $370(17.0)$ & 5400 \\
Lower extremities & $179000(16.5)$ & $976(44.8)$ & 700 \\
Superficial/wounds & $460000(42.4)$ & $324(14.9)$ & 1400 \\
Other & $103000(9.5)$ & $144(6.6)$ & 2000 \\
Total & $1084000(100)$ & $2177(100)$ & \\
Scenario & & & 2400 \\
Fall, not at home, non-traffic & 164000 & 400 & 5000 \\
Fall at home & 114000 & 573 & 2100 \\
Single bicycle accident & 54000 & 114 & 3200 \\
Car occupant & 32000 & 104 & 2600 \\
Moped user & 21000 & 54 & 3900 \\
Cyclist struck by car & 9100 & 42 & 5500 \\
Motocyclist & 8400 & 32 & \\
Pedestrian & 5900 & & \\
\hline
\end{tabular}




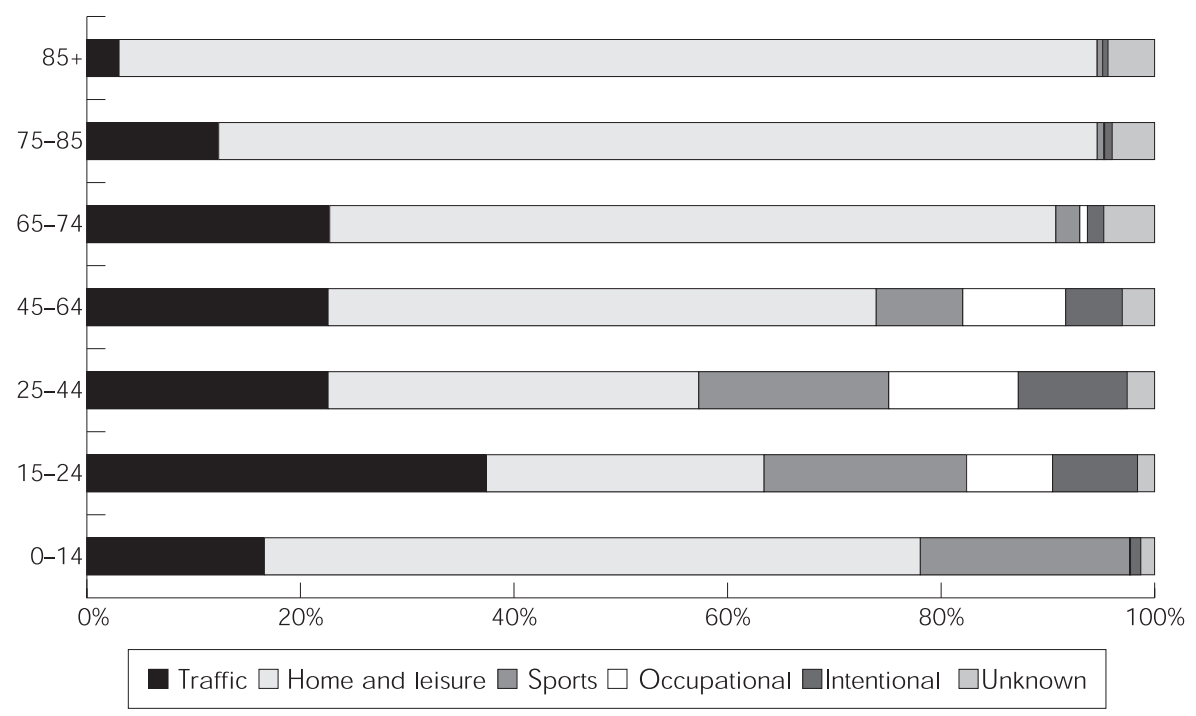

Figure 1 Share of categories in costs per age group: the Netherlands, 1997.

estimated at almost 2.2 billion guilders, an average of 2000 guilders for each injury patient who visits the emergency department.

\section{Incidence and costs by category}

Table 2 shows that home and leisure injuries account for over half of the total, followed by sports (17\%), and traffic (13\%). Home and leisure also account for the most costs (59\%), followed by traffic $(19 \%)$ and sports $(10 \%)$. The costs per patient show large variation among categories. They are highest for traffic, followed by home and leisure and intentional injuries. The observed variation is due to large differences in health care use by category.

The major group for all ages is home and leisure, varying from $37 \%$ for $15-24$ year olds to $90 \%$ for those 85 or older. The picture changes somewhat for the most costly injuries by age group (fig 1). Costs in the $0-14$ and $65+$ age groups are still dominated by home and leisure injuries, with traffic, however, becoming more prominent in the 15-24 age group.

\section{Incidence and costs by injury type}

Injuries to the lower extremities account for almost half of total injury costs (about 1 billion guilders) but only one sixth of injury incidence. Superficial injuries (such as contusions) and wounds are the most common (42\% of the total), but account for a lower proportion of the costs (15\%). Home and leisure injuries account for most lower extremity injury costs (69\%, see fig 2$)$, particularly for hip (85\%) and pelvic fractures $(66 \%)$. Traffic injuries are a major source of head injury costs (42\%), especially concussions (47\%) and other skull and brain injuries (50\%). Traffic also accounts for a large share of trunk injuries (40\%), particularly injuries to internal organs (44\%). For sports, the upper extremities dominate injury costs (15\%), especially luxations and distortions of the wrist, hand and fingers $(28 \%)$, and hand and finger fractures $(23 \%)$. Occupational injuries account for a relatively high share of superficial injuries and wounds (10\%) and of facial injuries (10\%). Intentional injuries also make a large contribution to the costs of facial injuries (15\%).

\section{Incidence and costs by scenario}

The model's potential use for specific policy issues is examined through scenarios consisting of any combination of LIS variables (for example, age, sex, type of injury, injury mechanism, place of occurrence) (table 2). For home and leisure, falls at home were responsible for $45 \%$ of the costs and

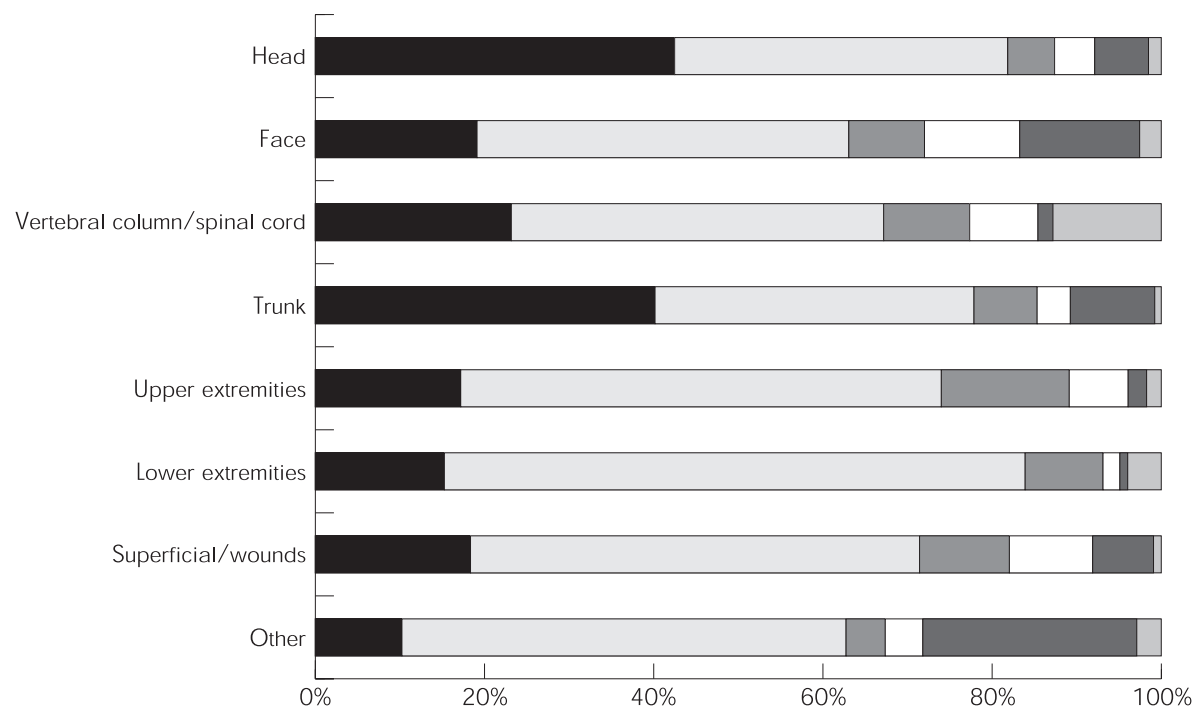

Figure 2 Share of categories in costs per injury type: the Netherlands, 1997.

Traffic $\square$ Home and leisure $\square$ Sports $\square$ Occupational $\square$ Intentional $\square$ Unknown 
$20 \%$ of the incidence and therefore are clearly a priority area in injury prevention. Bicycle injuries not involving other road users comprised $38 \%$ of all traffic injuries, accounting for 114 million guilders: another priority area.

The model provides still more detail. For example, $45 \%$ of bicycle victims were female yet they accounted for $53 \%$ of the costs. For children under 5, the costs are mainly due to lower extremity injuries, excluding fractures of the upper leg (37\%) and superficial injuries and wounds (35\%). Almost half of the costs $(47 \%)$ for those 55 years and older are related to hip and upper leg fractures $(47 \%)$.

\section{DISCUSSION}

When used in combination with routine injury surveillance systems (for example, LIS), our model provides a coherent picture of the costs and incidence of injuries and related health care use. Differentiation can also be made according to health care sector, category, age, sex and injury group, and various combinations thereof. The results are an easily interpretable public health indicator that integrates patient data from various sources under one common denominator: money.

For example, we identified bicycle injuries as a priority in the Netherlands because skull and brain injuries account for $5 \%$ of the incidence and $9 \%$ of injury costs ( 11 million guilders). Our model calculates that every skull and brain injury that can be prevented would save on average 4400 guilders. International literature indicates wearing a helmet could reduce these injuries by between $45 \%$ and $80 \% .{ }^{27-30}$ In 1997, few cyclists wore helmets in the Netherlands. Assuming that half could be persuaded to do so (by legislation and/or education) and that $50 \%$ of the skull and brain injuries could be prevented, the number of these injuries could be reduced from 2500 to 1900 per year, yielding a savings of 2.7 million guilders.

The model provides insight into injury costs in the Netherlands for all injuries and specific types of injuries. Hence, it is an important addition to existing epidemiological (for example, death and injury statistics) and healthcare data (for example, numbers of hospitalised patients). Epidemiological and cost data can be used to prioritize injuries for prevention. Unravelling the epidemiological criteria (for example, magnitude and severity) and intervention criteria (for example, availability of suitable, efficient, and effective interventions) leads to a more transparent discussion on prioritisation. ${ }^{31}$ Ethical, social, and other factors also play a part in the prioritisation of public health policy. ${ }^{32}$

The incidence based approach of the model also allows preventive measures to be evaluated prospectively or retrospectively in terms of cost and health effects and can be used to estimate the effect on healthcare and costs when shifts occur from one health care segment to another (for example, a shift from inpatient care to day care).

\section{Limitations}

Several methodological and data limitations must be considered in this model. ${ }^{13}{ }^{17}$ One major issue is that transition probabilities could not be estimated by linking LIS incidence data to the other health care registries at the level of individual patients. Instead, calculations had to be made at the group level. A patient diagnosis, however, may change while in care. A comparison between LIS diagnostic data and hospital discharge records (LMR) revealed diagnostic shifts at the group level. This phenomenon, dubbed "diagnosis migration", may lead to overestimation of some injury costs and underestimation of others. Moreover, as with all models, the validity strongly depends on the quality of the data. An important aspect of our major data sources is that they are nationwide (LMR, LIVRE, SIVIS) or use a broad ranging random sample
(LIS). Therefore, estimates of emergency transport and intramural care are probably reliable and these sectors account for $70 \%$ of injury costs. Estimates of outpatient care are less certain as they were derived from a patient survey with a $40 \%$ response. Given these potential sources of error, it will be necessary to conduct sensitivity analyses when the model is used for specific policy issues.

The model needs to be regularly updated with new health care and cost price data and further research is needed to refine the cost estimates. Other information about societal costs is also relevant to policymaking. Hence, the model needs to be extended to include such costs (for example, sick leave) and information on the burden of disease and death such as expressed in disability adjusted life years. ${ }^{33}$

\section{IMPLICATIONS FOR PREVENTION}

The total health care costs generated by injuries indicates the relative importance of injuries in the health sector as a whole and may be useful in convincing politicians to put injuries on their agenda. When comparisons are drawn between different public health problems it is best to use studies that apply a uniform method to calculate the costs. Our model is linked to a continuous surveillance system (LIS) that makes it possible to plot injury related trends in health care and costs, and to anticipate future scenarios. This makes it an ideal tool for policy priority setting by identifying injuries to be considered for potential intervention.

\section{ACKNOWLEDGEMENTS}

We acknowledge the input of the members of the European Working Group on the Costs of Injury in the development of the outline of the model.

Authors' affiliations

S Mulder, Consumer Safety Institute, Amsterdam, the Netherlands W J Meerding, E F van Beeck, Department of Public Health, Erasmus University Rotterdam, Rotterdam, the Netherlands

\section{REFERENCES}

1 World Health Organization. Health 21: the health for all policy framework for the WHO European region. Copenhagen: World Health Regional Office for Europe, 1999.

2 Consument en Veiligheid. Werkboek letsel informatie systeem (LIS). Amsterdam: Consument en Veiligheid, 2000.

3 Dekker R, Pruymboom C, Toet H. LIS jaaroverzicht 1998. Amsterdam Stichting Consument en Veiligheid, 2000.

4 Polder JJ, van der Maas PJ. Kosten van ziekten in Nederland 1994. Rotterdam: Erasmus Universiteit, Instituut Maatschappelijke Gezondheidszorg, Instituut voor Medical Technology Assessment, 1997.

5 Beeck EF van, van Roijen L, Mackenbach JP. Medical costs and economic production losses due to injuries in the Netherlands. J Trauma 1997:42:1116-23.

6 Hartunian NS, Smart CN, Thompson MS. The incidence and economic costs of cancer, motor vehicle injuries, coronary heart disease, and stroke: a comparative analysis. Am J Public Health 1980;70: 1249-60.

7 Vejdirektoratet. Road accident costs. Copenhagen: Vejdirektoratet, 1983.

8 Rice DP, Mackenzie EJ, eds. Cost of Injury in the United States: a report to Congress. San Francisco: Institute for Health and Ageing, University of California, 1989

9 Koopmanschap MA, van Roijen L, Bonneux L. Kosten van ziekten in Nederland. Rotterdam: Instituut Maatschappelijke Gezondheidszorg, Erasmus Universiteit Rotterdam, 1991.

10 Bensch D. Gesamtwirtschaftliche Auswirkungen der Unfälle in den Bereichen Heim, Freizeit und Sport. Wien: Sicher Leben, 1995.

11 Lawrence BA, Miller TR, Jensen AF, et al. Estimating the costs of non-fatal consumer product injuries in the United States. Injury Control \& Safety Promotion 2000;2:97-113.

12 Mulder S, Beeck van EF, Meerding WJ. New directions in injury surveillance: development of a model for continuous monitoring of direct medical costs. International Journal of Consumer and Product Safety 1999;6:1 1-23.

13 Meerding WJ, Birnie E, Mulder S, et al. Costs of injuries in the Netherlands. Amsterdam: Consumer Safety Institute, 2000.

14 National Database of Hospitalised Patients (LMR). Databases of admissions and operations of 1996 and 1997. Utrecht: SIG.

15 National Information System for Rehabilitation (LIVRE). Database of discharged patients of 1996. Utrecht: VRIN. 
16 Nursing Home Information System (SIVIS). Databases of admitted and discharged patients of 1996. Utrecht: SIG.

17 Meerding WJ, Birnie E, Mulder S, et al. Kosten van letsels door ongevallen in Nederland: wetenschappelijke verantwoording. Amsterdam: Consument en Veiligheid, 2000.

18 Council for Healthcare Budgeting (COTG). Tariffs: general practitioners, medical specialists and operational costs. Utrecht: COTG, 1997.

19 Nationaal Ziekenhuisinstituut. Financiële statistiek verpleeghuizen voor somatische patiënten 1997. Utrecht: Nationaal Ziekenhuisintituut, 1998

20 Nationaal Ziekenhuisinstituut. Financiële en productiestatistieken algemene, academische en categorale ziekenhuizen. Utrecht: Nationaal Ziekenhuisintituut, 1999

21 Ziekenfondsraad/SEA. Jaaroverzicht 1997: financiële statistieken Ziekenfondswet en AWBZ. Utrecht: Ziekenfondsraad/SEA, 1998.

22 Centraal Bureau voor de Statistiek. Algemene gegevens van de intramurale gezondheidszorg 1997. Maandbericht Gezondheidsstatistiek 98/10. Voorburg, Heerlen: Centraal Bureau voor de Statistiek, 1998.

23 Statistics Netherlands. Costs of health care 1997 (www.cbs.nl).

24 Ministerie van Volksgezondheid en Sport. Jaaroverzicht Zorg 1998. 's Gravenhage: SDU, 1999.

25 Mulder S, Beeck EF van, eds. Measuring the burden of injuries. Amsterdam: European Consumer Safety Association, 1999.

26 Mulder S, Larsen CF, Meerding WJ, eds. Glossary of terms for costs of injury studies. Amsterdam: European Consumer Safety Association, 1998
27 Sacks JJ , Holmgreen P, Smiths SM, et al. Bicycle associated head injuries and deaths in the United States from 1984 through 1988: how many are preventable? JAMA 1991;266:3016-8

28 Thomas, S, Acton C, Nixon J, et al. Effectiveness of bicycle helmets in preventing head injury in children: case-control study. BM 1994;308: 173-6.

29 McDermott FT. Bicyclist head injury prevention by helmets and mandatory wearing legislation in Victoria Australia. Ann R Coll Surg Engl 1995:77:38-44.

30 Thompson DC, Nunn ME, Thompson RS, et al. Effectiveness of bicycle safety helmets in preventing serious facial injuries. JAMA 1996;276:1974-5

31 Mulder S, Blankendaal F, Vriend I, et al. Epidemiological data and ranking home and leisure accidents for priority-setting. Accid Anal Prev (in press).

32 Rogmans WHJ. Injury cost-analysis and ethics: at what costs? International Journal of Consumer and Product Safety 1999:6:3-9.

33 Murray CJL, Lopez AD, eds. The global burden of disease. Volume 1: a comprehensive assessment of mortality and disability from diseases, injuries and risk factors in 1990 and projected to 2020. Cambridge, Massachusetts: Harvard School of Public Health on behalf of the World Health Organization and the World Bank, 1996.

34 Dutch Injury Surveillance System (LIS). Database of 1997. Amsterdam: Consumer Safety Institute.

35 Academisch Ziekenhuis Utrecht. Databases of injury patients who attended the emergency department in 1995 and 1996. Utrecht: Academisch Ziekenhuis Utrecht.

\title{
CONFERENCE
}

\section{6th World Conference on Injury Prevention and Control}

\author{
12-15 May 2002, Montréal, Canada
}

\begin{abstract}
he Organizing Committee is very pleased to invite you to take part in the 6th World Conference on Injury Prevention and Control which will be held from May 12 to 15, 2002 at the Montréal Convention Centre. This meeting, on the theme of Injuries, Suicide and Violence: Building Knowledge, Policies and Practices to Promote a Safer World, will be an excellent opportunity for the participants to exchange information and forge links between sectors (health, transportation, safety, justice, etc) and, together, find new ways to improve the safety of populations and reduce the burden of injuries. The conference will deal first of all with safety problems in various contexts: on the road, in the workplace, in the home, and during recreational and sports activities, as well as the problems of suicide, violence, and post-trauma care. Each of these themes will be discussed extensively during the three days of the conference, which will include oral presentations, round tables, debates, and presentations on the most recent scientific advances.

In addition, cross disciplinary topics that are of interest to all the participants will be presented in plenary sessions to stimulate exchange between sectors and fields of specialty. Finally, satellite conferences, courses, site visits, and exhibits will complete the program. To ensure the quality of the scientific content of the conference, working groups bringing together leaders from each field have been established. For the second time, this conference will take place in the Americas, which is why we are extending a very special invitation to our colleagues from Latin America. Montréal is a beautiful city, well known for its joie de vivre. It has a reputation for hospitality and safety, and also has a cultural heritage that is well worth discovering. We look forward to seeing you in Montréal in May 2002 at the 6th World Conference.

For registration, accommodation, and abstract submission forms and for more information, please consult the conference web site at http://www.trauma2002.com or contact the Conference Secretariat at + l 5148481133 (fax + l 514288 6469).
\end{abstract}

